Villard; although in general full justice is done to the subject-matter of their contributions. The inclusion of a description and diagram of a mechanical rectifier (pp. 183, 184) is somewhat surprising. The authors have shown great skill in the selection and discussion of the matter included in the book. They have met in advance any possible objection which might be raised to the restricted treatment or rejection of any topic by including a good bibliography of references. The book should be found in all radiological libraries, and is certain to achieve a well-deserved popularity among medical students and those who desire to become qualified radiologists, whether medical or industrial.

F. L. Hopwoon.

\section{ELECTRIC POWER CONTROL}

\section{Electric Power System Control}

By H. P. Young. (Monographs on Electrical Engineering, Vol. 11.) Pp. xii $+319+22$ plates. (London : Chapman and Hall, Ltd., 1942.) 25s. net.

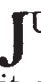

UST as ordered control is the keynote of success of the individual and of the organization, so is it when applied to the harnessing of the forces of Nature, either in their pristine state or as manifested in the workings of man-made mechanisms. In the electrical field of endeavour, intelligent control is a vital necessity, and it finds its highest expression in the various forms of automatic apparatus and systems which are so largely responsible for the modern reliability of electric power supply. It is no exaggeration to say that the extensive interconnected high-voltage power systems of to-day with their hundreds of thousands of rated kilowatts and millions of potential fault kilowatts owe their operational success and, indeed, their very being, to automatic control and protection. A book such as this, which brings the subject before the reader as a co-ordinated whole, is, therefore, a valuable addition to electrical engineering literature and is welcome accordingly.

The opening chapter is of an introductory nature and discusses the parallel eperation of generators and the characteristics of exciters. Two chapters follow, on the automatic regulation of both voltage and power factor of synchronous machines, stress being laid upon the importance of the subject from the point of view of system stability. The succeeding chapter is devoted to the synchronizing of alternators, an operation which it is essential should be carried out accurately to avoid high-magnitude current surges.

Power control by reactance is a technique which has been adopted for many years on large systems in respect of machines, busbars and feeders, and Chapter 5 describes the principles and application of the different methods and apparatus. Chapters 6 and 7 deal with circuit breakers, circuit interruption, power station switchgear arrangements, and shortcircuit calculations, and they form a reliable guide to modern practice and developments in these important branches of power control.

The last three chapters relate respectively to the interconnexion of power stations, interconnector control, and automatic supervisory control. These are all features of power system operation which are rather imperfectly understood by most engineers apart from the control specialists and hence are valuable additions to the book.

It would be easy to suggest additional studies which the author might have included, but nothing which might have been omitted. Within the confines which have been laid down, the book is an eminently suitable guide to electrical engineers interested in both the design and operation of power system networks.

\section{ENGINEERING DATA}

The Engineer's Year-Book of Formulæ, Rules, Tables, Data and Memoranda for 1943

A Compendium of the Modern Practice of Civil, Mechanical, Electrical, Marine, Gas, Aero, Mine and Metallurgical Engineering. Originally compiled by H. R. Kempe and W. Hanneford-Smith. 49th annual issue, revised under the direction of L. St. L. Pendred. Pp. xii $+2854+$ lxxxi. (London: Morgan Brothers (Publishers), Ltd., 1943.) 40s. net.

D ESPITE the difficulties associated with war conditions, "Kempe" has once more appeared in a new edition - the forty-ninth-and, certainly as regards its external appearance and form, is but little different from its more recent predecessors. Internally, too, there is little change from last year's issue, which was made the occasion of one of those periodical revisions by which from time to time it renews its youth.

In the present issue, then, one would expect to find a number of minor corrections rather than any alterations in the body of the work. As it happens, however, very little correction proved to be necessary, and the principal change is found in the sub-section devoted to fire extinction and prevention, which has been revised and amplified by Hubert B. Graham, president of the Fire Extinguisher Trades Association. This forms Part IV of Section XXXVI and, in the space available, deals in considerable detail, though necessarily succinctly, with first-aid pre. cautions and appliances, mobile secondary-aid and major appliances, fixed installations, fire hose, pressures to give various ranges of fire streams with different sizes of nozzle, fire-resisting buildings and materials, fire prevention at sea and oil fires. The collated information regarding the different types of extincteurs, their charges, their capacity and their applications should prove most valuable.

It is difficult to present the scope of "Kempe" to anyone who has not handled the book itself in recent years. The bibliography shows a number of 'continents' into which its world can be divided, but in each of these there are major and minor subdivisions almost beyond enumeration or description. Its 2,751 pages, exclusive of the index, which occupies 72 pages - a fact which, in itself, is illuminating as to the variety of items dealt with-are allocated to no fewer than forty-seven main sections. These are very largely devoted to the practical side of en. gineering, and include such representative titles as surveying, reinforced concrete, aircraft and aeroengines, radio communication and electric traction, to name but a few. In contrast with these a fair proportion deal with more fundamental subjects such as mechanics, heat, and acoustics. A third group includes those giving information on patents, designs and trade marks, depreciation of plant and machinery, income tax allowances, and legal notes for engineers. Thus it can be seen that "Kempe" is eminently a book for every engineer's desk, and one capable of informing him on many points requiring confirmation or elucidation. 